\title{
Biomedical grant awarded by 'American Idol'-style public vote
}

BOSTON - With so many top-notch research proposals seeking funding but only limited grant money to go around, deciding which among the best of the best projects to support is no easy task. What if you have a number of equally commendable applications and you don't know how to break the tie? Usually, a panel of experts will weigh the merits of the various projects and come to some consensus behind closed doors. But in an unconventional twist, the Brigham and Women's Hospital (BWH) has opted to let the general public act as scientific judge and jury.

After six weeks of online voting and nearly 6,500 votes cast, the decision was in. On 15 November, the Harvard-affiliated hospital announced that a project designed to explore how best to integrate genomic sequencing into routine medical care for healthy newborns had won the inaugural BRIght Futures Prize. The project's leader, clinical geneticist Robert Green, and his team received a $\$ 100,000$ research grant from the BWH's Biomedical Research Institute (BRI).

It may sound akin to a popularity contest, but Jacqueline Slavik, executive director of the BRI, maintains that the decision process was scientifically "solid," as every research proposal "went through all of the traditional scientific review steps and a rigorous peer review" before reaching the final voting stage.

First, review committees with expertise in personalized medicine and systems immunology - the two subject areas for which the BRI solicited proposals for the prizewinnowed the list of applicants down to a series of semifinalists. Each selected applicant then made an in-person pitch to the BRI's Research Oversight Committee, which ultimately chose the three proposals that were presented to the public. Finally, the three research groups behind those projects worked together with the hospital's public affairs team to create a series of videos and brief nontechnical descriptions about the proposals that were hosted on the voting site.

"It's a new way of trying to decide who gets the money when you have equally meritorious projects," says Slavik. "We could flip a coin," she quips. Instead, by engaging the public, "we achieve several goals at once," without sacrificing scientific rigor.

"Our goal was really to engage the Brigham community at large," notes Lesley Solomon, director of strategy and innovation at the BRI. "We want the world to know about the breadth and depth of the research that goes on here."

The organizers of Grand Challenges Canada, a global health initiative funded

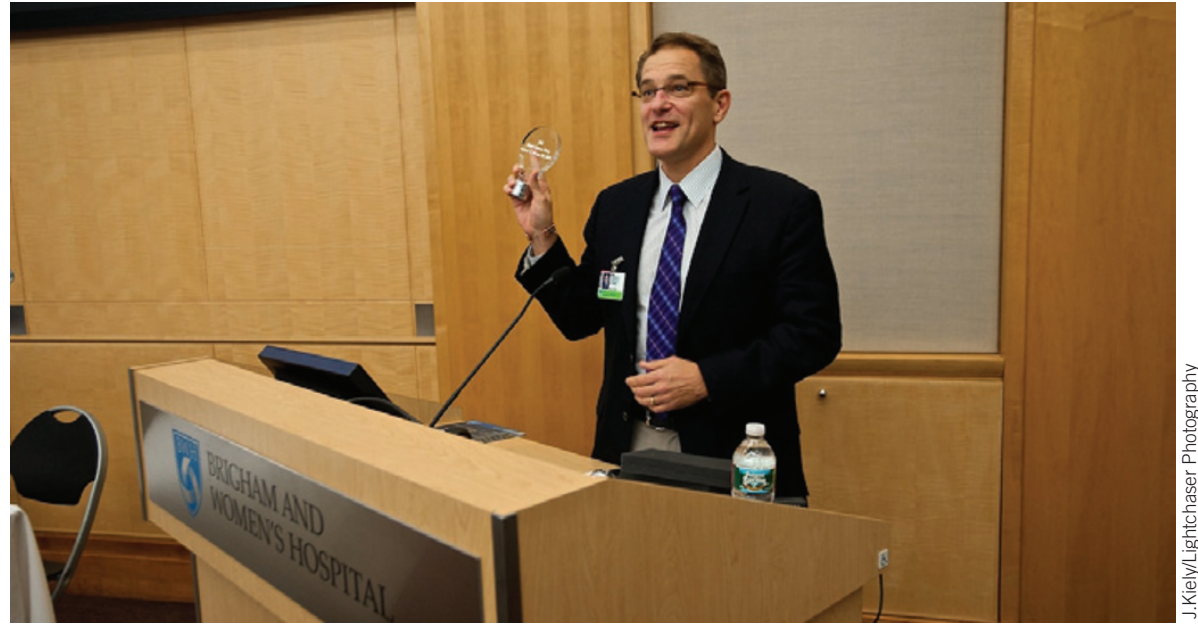

Light-bulb moment: The public chose Robert Green's proposal to explore sequencing in newborns.

by the Canadian government, adopted a similar strategy for their Stars in Global Health program, which last month provided $\$ 100,000$ seed grants to each of 68 scientists from across Canada and the developing world. Applicants to the program, which was first launched last year, had to include two-minute videos explaining the impact of their proposed research in a lay-friendly manner. The public then watched and 'liked' the videos, with both the videos themselves and the public response helping to inform the peer-review committee's assessment, although they did not serve as the ultimate determinant of who received funding.

"We often think about science over here and social entrepreneurship over there," says Peter Singer, chief executive of Grand Challenges Canada and the director of the Sandra Rotman Centre in Toronto. "My hypothesis is that these videos and the votes serve as a bridge between those two worlds in the context of the peerreview process."

\section{The people have spoken}

Experts involved in peer review and grant funding commend the efforts at public engagement. "In determining which [proposals] will have the most scientific impact, this is not the way I would choose. However, if one was also interested in getting the public into research more, this is an interesting approach," Richard Nakamura, acting director of the Center for Scientific Review in Bethesda, Maryland, which oversees the peer-review process for the majority of research grant applications submitted to the US National Institutes of Health (NIH), says of the BRIght Futures Prize selection process.
"This could have some larger ripple effects."

Robert Plenge, a rheumatologist and geneticist at $\mathrm{BWH}$, is already seeing those effects. For the prize, he proposed to study the molecular signature generated by people with rheumatoid arthritis in response to antiinterleukin-6 therapy. After being selected as a finalist, several small news outlets in his local town of Wellesley, Massachusetts, ran articles and broadcasts featuring his work. "Suddenly, I could talk to friends and neighbors who aren't in science about what I do for a living," Plenge says. "At the end of all this, even though I didn't win the prize, I have actually benefited from the process."

Other entrants had similar experiences. The prize "gave us an opportunity to share what we were doing on Facebook and other social media, and I was actually surprised by the responses I got," says Green. One friend wrote that sequencing newborns sounded like something out of the movie Gattaca. A college roommate who is also a pediatrician expressed concern with some of the ethics of the project. "There was engagement at levels I hadn't quite expected," Green says, "and that was kind of fun."

In addition to his prize-winning project, Green is also leading a $\$ 9.6$ million clinical trial funded by the NIH called MedSeq designed to study the use of whole-genome sequencing in routine medical practice among adults. $\mathrm{He}$ hopes that the seed money provided by the BRIght Futures Prize will help him secure NIH funding for a similar study in infants. He even has a name for that proposed project. He calls it BabySeq.

Elie Dolgin 